\title{
Evaluation of patient's knowledge and perceptions regarding generic medicines - pilot study in Saragossa (Spain)
}

\author{
Mar Gimeno ${ }^{\mathrm{a}}$, Isabel San Gil ${ }^{\mathrm{b}}$, Dr. Manuel Gómez ${ }^{\mathrm{c}}$, Laura Lomba ${ }^{\mathrm{c}}$ \\ ${ }^{a}$ PhD student, Pharmacist. Universidad San Jorge ${ }^{b}$ Pharmacist ${ }^{c}$ Professor Pharmacy Degree. Health Sciences \\ Faculty. Universidad San Jorge \\ Correspondence to: Mar Gimeno. Universidad San Jorge. Campus Universitario Villanueva de Gállego. \\ Autovía A-23 Zaragoza-Huesca Km. 299. 50.830 - Villanueva de Gállego (Zaragoza) Spain.
}

\begin{abstract}
:-
Objective The aim is to review the actual knowledge and perception of generic medicines in Spain to see if more training and information for the patients is necessary.

Method

Self-administered questionnaires were used to survey the patient's knowledge and perceptions of generic medicines. The questionnaires were built with an expert panel. The pilot was conducted in Saragossa province (Spain).

Results

Patients with a low educational level and those older than 51 years had a worse attitude to generics regarding their equivalence, quality and efficacy. Also showed the general non-acceptance of the substitution policy switching from branded to generic medicines.

\section{Conclusions}

More educational actions and campaigns directed to patients were shown to be necessary in order to improve the knowledge of generic drugs, specially focused on groups with negative perceptions.

Practice implications

Educational activities, direct and individual about security and efficacy of generic medicines increase its acceptance and appreciation. Health professionals (doctors, pharmacists and nurses) are the ones in the best position to develop this educational work. There is a need of a bigger effort in the country on generics information, especially in the group of older than 50 years old and in the lower education group.
\end{abstract}

KEY WORDS: generic medicine; perception; knowledge; patients; generic substitution.

\section{INTRODUCTION}

Spain is one of the countries reporting the biggest total consumption in medicines and other pharmaceutical products, with an expense representing a 1.77\% of the Gross Domestic Product (GDP) in 2012. Since 2009 Spain has been able to reduce its pharmaceutical cost average per inhabitant, going from $273 €$ in that same year to $212 €$ in $2011 .{ }^{1}$ This situation is the result of the different policies the Spanish government has implemented in order to stop the increase of the pharmaceutical cost of the "Sistema Nacional de Salud", the National Healthcare System in Spain, including the preferred usage and substitution policies of generic medicines. However, although the increase of use of generic medicines has been promoted in the last years as an efficient and fast tool of saving for the public health administration, Spain is one of the countries with lower generic medicines penetration, with a market share of $17.4 \%$ in the first quarter of $2013{ }^{2}{ }^{2}$ This share is still small and far away from other market shares in other European countries such as Poland, UK or Germany and there are no expectations on a big increase of their market share neither on an increase on the usage of medicines in Spain until 2015.,4

As a result, we find important to analyze the different factors that could influence the generic medicines consumption and especially the attitude of the patients, as they are the main player affected when a change of health policy happens. There are not so many researches about knowledge and perception on generic and branded medicines by Spanish patients, so we consider that more research is needed in this field. Health Authorities need to know the knowledge and adherence to those policies by the players in the medicines chain, as their actions should be different relating to the results.

As many countries are going through the same processes to switch to a generic medicines focused market (in different levels of maturity), it is an interesting study for an international audience in case they want to conduct similar studies in order to decide actions, if needed, to increase the generic market, as other studies show. The goal of this research is to evaluate the perception, opinion, knowledge and adherence to the health policy of generic medicines prescription and dispensing by the patients, the final users of the generic medicines. 
Additionally we would like to understand their perception of security, quality and efficacy of the generic medicines.

\section{METHOD}

In this research we followed the general building surveys process steps. ${ }^{5}$ The research was conducted in Saragossa province in Spain, as a pilot of a later research at national scale. Saragossa's special characteristics and medium size can be considered a representative city in the Spanish market, so it's a good place to conduct a pilot research prior to a national research. ${ }^{6}$ This research has been conducted in the steps defined below, questionnaire development, validation by experts and survey conduction. Afterwards statistical treatment and analysis of data was done.

\section{QUESTIONNAIRE DEVELOPMENT}

A. Topic specification and type of instrument

We developed structured questionnaires that were administrated by a surveyor. The topic is the perception of generic medicines and its prescription, dispensing and usage.

B. Items and format generation

To generate the items of the survey, we made an exhaustive bibliographic research on surveys conducted in other countries or in Spain about perception and/or knowledge at generic medicines. Once all the relevant items were gathered, we aggregated them by theme.

The survey was divided in 3 parts:

1. Demographic data of the patient

2. Generic medicines Knowledge

3. Perception and attitude against generic medicines

For each item in part 2 and 3 of the survey, we used an additive valuation scale (Likert type) or a closed answer of Yes, No, NR (No response). Each item is presented as a positive closed statement followed by different answer options that indicate different agreement or disagreement levels. To each answer a specific grade is given (from 1 to 5), being able then to calculate the total result by adding the grade of each item if needed. Last question of part 3 has a multi-option answer.

Number of items in the survey:

We chose 4 items for "knowledge of EFG" and $6+1$ for the "perception" part. This last question $(+1)$ is the only question with multi-option answer.

\section{REVIEW AND VALIDATION OF THE QUESTIONNAIRES BY AN EXPERT PANEL}

The review of the items in the survey was done with the Delphi methodology, but with the warranty, as the methodology indicates the confidentiality of the different expert opinions and without any opinion interchange between them and trying to look for the agreement of the participants. ${ }^{7,8}$ The review was done in an anonymous way. For each item a questionnaire was given with the questions from figure 1 and closed answer Yes/No, except for one, where they had free text to rephrase the question. (Figure 1: Expert panel review questionnaire)

As an expert panel, 10 health professionals were chosen (doctors, nurses and pharmacists), all of them working in Spain but not in Saragossa province and without any relation and conflict of interest with this research. They were contacted separately by email and received their answer in the same way. Two cycles were done, between April and July 2013 until they got an agreement on the final items of the survey. All the process was done without direct contact between the experts..

In both cycles an introductory letter was sent with an explanation of the goal of the research and their opinion.

After the first cycle, where all the items were sent with the specific questionnaire, all the answers were collected anonymously in an Excel data base for its analysis. First results were:

- with $100 \%$ of positive answers about the order of the items.

- some suggestions to rephrase some of the questions

- include more options in the multi-option question (last question in the survey).

After small adjustments taking into account those proposals, a second cycle was conducted, with $100 \%$ consensus in the final survey.

\section{SURVEY CONDUCTION}

A. Survey participants: exclusion and inclusion criteria

1. Inclusion: patients or carers living currently in Saragossa that know how to read and write 
2. Exclusion: patients or carers not living currently in Saragossa or that don't know how to read and write

B. Sampling procedure and sample size

Bibliography indicates that minimum of 5 people should be interviewed per item of the questionnaire, and that is not recommended to have less than 100 people interviewed in overall to achieve consistent results. That's why our goal in this pilot was to survey a minimum of 100 people interviewed. ${ }^{9,}{ }^{10} \mathrm{We}$ concluded the study with 168 surveys.

Total population in Saragossa province was 978.130 inhabitants in 2012 (Ministerio de Economía y Hacienda (29 de diciembre de 2012). «Real Decreto 1697/2012, de 21 de diciembre, por el que se declaran oficiales las cifras de población resultantes de la revisión del padrón municipal referidas al 1 de enero de 2012». (http://www.boe.es/boe/dias/2012/12/29/pdfs/boe-a-2012-15714.pdf) Boletín Oficial del Estado. Checked 2nd January 2013)

C. Instrument

Anonymous questionnaires structured and self-administrated with a surveyor.

D. Procedure of survey

Patients and carers had the support of surveyors not related to and without any interest out of this research in a pharmacy in the city center of Saragossa city. Surveyors were trained previously in order to help and solve questions from the patients.

E. Collection of data period

Results were collected between December 2013 and February 2014.

F. Research scope

The research, as stated before, is a pilot done in Saragossa province in Spain. After the results out of this research, it will be decided if it's needed another research in a country level.

G. Aggregation and data analysis

A database was created to collect and aggregate the received data. For the summary, we considered that the patients agreed if the answer was "agree" or "completely agree" and considered that they didn't agree if the answer was "disagree" or "completely disagree" Neutral answers, were not considered as positive answers.

Statistical treatment and data analysis:

We conducted a descriptive analysis of the studied sample for all the collected variables and we determined the association between the qualitative variables with the Chi-squared test. The results were expressed as the frequency of answers for each of them and by percentages. We considered statistical significant the differences with a value $\mathrm{p}<0.05$. The analysis was done with the system SPSS version 19.0 (SPSS-PC, Chicago, EE.UU.).

\section{Demographic data}

\section{RESULTS}

In total, 168 surveys were conducted, of which 3 were not completed. Average of participants was in the range between 31 and 50 years old and almost two thirds were women. More than $80 \%$ had professional education, medium studies or university degree. From job perspective, only $7 \%$ was unemployed, $14 \%$ were retired and $2 \%$ were students. (Table 1: Demographic data.)

A $57.6 \%$ of the patients took medicines in a regular basis, being distributed without big difference in the participants of more than 30 years old.

\section{Knowledge of generic medicines}

Although almost all of the patients (96.4\%) stated to know what a generic medicine is, almost $20 \%$ didn't know the difference between a generic and a branded medicine and more than one third of them indicated that didn't know the substitution process from a branded to a generic medicine. (Graph 1: General generic medicines knowledge)

Almost $65 \%$ of the patients agreed with the statement "I have enough information to understand all the medicines I take" and only $18.8 \%$ disagreed, being this group represented by females between 51 and 65 years old, with basic studies and currently employed. (Graph 2: Knowledge in generic medicines (\% of positive answers))

Knowledge by age. From age perspective, the participants older than 51 years old and younger than 30 years old declared in a biggest percentage not to know the differences between a generic and a branded medicine.

Regarding the knowledge on the substitution process between branded and generics, half of the participants between 51 and 65 years old stated to know it and they were the biggest group with this answer. The negative and indifferent answers about the substitution process had the biggest percentage in younger than 30 years old $(77.3 \%)$ and in older than 65 years old $(63.2 \%)$. Nevertheless, both groups stated that they accepted the substitution process, with $82 \%$ and $63.2 \%$ respectively.

One fourth of the participants between 51 and 65 years old stated not to have enough information to ensure that they understood all the medicines they took, although in the rest of the groups, this statement had only less of $20 \%$. 
Knowledge by education. Almost $20 \%$ of the participants with basic studies only didn't know what a generic medicine was. In the rest of the groups the percentage was not significant.

The group with the biggest percentage (72.2\%) that know the difference between generics and branded medicines was the one with university studies and the group with the less proportion (44\%) was the one with basic studies. To the question about the knowledge of the substitution process, we can see the percentages are lower. Again, the group with university studies was the one that stated to know it with the highest percentage (44.4\%), after the group with basic studies (40\%) and last the one with medium/professional studies (36.2\%).

Majority of the participants (77.1\%) with university studies answered positive to the question "I have enough information to understand the medicines I take". The percentages were lower with the group with medium/professional studies (63.8\%) and basic studies (48\%).

In table 2 (Table 2: Positive answers about generic medicines knowledge) we can see the percentage of participants that agreed or completely agreed with the statements about generic medicines knowledge, split by demographic groups.

Perception and attitude towards generic medicines. (Graph 3: Perception and attitude towards generic medicines (\% positive answers)).

The percentage of patients that declared not to know the differences between a generic medicine and a branded medicine and not knowing the substitution process was significantly bigger than those groups with a negative perception about equivalence, quality and effectiveness of generic medicines, being half of the answers negative or indifferent.

Equivalence and effectiveness. (Table 3: Positive answers about perception and attitude towards generic medicines. Equivalence and effectiveness). One fourth disagreed, although $61.8 \%$ of the participants agreed that generic medicines are equivalent to branded medicines and on this statement. And while 58.8\% disagreed that generic medicines were less effective than branded, $23.1 \%$ participants stated that they were less effective.

Majority of the participants that didn't consider generic medicines equivalent to branded or that they were less effective, also considered negative the quality of generics $(70-80 \%)$ and stated that they had more secondary effects than branded $(40 \%)$. It is important to say that although almost one fourth of the ones that stated that effectiveness is less in generics, they accept the substitution process. Also almost one third of those participants said they didn't have enough information about the medicines they take.

Perception by age. Almost $40 \%$ of the participants with ages between 51 and 65 years old answered that generic were not equivalent to branded medicines, but this answer was lower in the rest of the groups (lower than 26\%) Also, one third of the participants between 51 and 65 years old stated that generic medicines were less effective than branded and $40 \%$ in this same group said they didn't accept the substitution process between branded and generic medicines. In the group of more than 65 year old $31.6 \%$ stated that generics were less effective than branded.

Perception by education. About the statement "generic medicines are equivalent to branded medicines" the results were similar to the analysis above. A total of $74.4 \%$ of the participants with university degree agreed with the statement, against only $11 \%$ that disagreed. In the medium/professional education group we had $51 \%$ that agreed against only $28.3 \%$ that disagreed and the proportion of those answers in the basic studies group was $44 \%$ and $48 \%$ respectively. As we can see, the positive perception is lower as lower is the education level and also the negative perception is higher as lower is the education level; indifference is not significant, about $10 \%$ in all cases.

With the statement "generic medicines are less effective than branded medicines", the participants with university degree were the ones that agreed less $(13.3 \%)$ meanwhile the other participants increased this proportion to 35\% approximately. Indifference answers were similar in all groups.

Quality and secondary effects. With questions about quality, the percentage of participants that said that the generic medicines have different quality from branded, was up to $26.7 \%$. Nevertheless, only $11.5 \%$ of the participants stated to agree that generic medicines have more secondary effects than branded.

Only $36 \%$ of the participants that stated that the quality in generic medicines is not the same as branded also stated that generic have more secondary effects, but they did agreed in majority that they are not equivalent to branded medicines and that they are less effective than these (66\% and $71 \%$ each). $36 \%$ from this group accepts the substitution process. Table 4: Positive answers about perception and attitude towards generic medicines. Quality, expense and acceptance.

By age. More than one third of the participants between 51 and 65 years old (36\%) answered that generics have different quality than branded, but only $19,4 \%$ of these had the opinion on the generics having more secondary effects tan branded.

By education. When talking about the perception of the quality of the generic medicines, the group with professional or medium education was the one that answered in bigger proportion, with a $44 \%$ of their answers, that the generics have different quality tan the branded, being this percentage a $32 \%$ in the case of basic studies and $15,6 \%$ in participants with university degree. Nevertheless, when asking about the security of generics, the 
participants with basic studies were the ones that stated in higher percentage, $28 \%$ of the answers, that the generics had more secondary effects than the branded, meanwhile $15 \%$ and $5.6 \%$ of the participants with medium studies and university degree answered the same in this question.

Generic medicines and health policies. Table 4: Positive answers about perception and attitude towards generic medicines. Quality, expense and acceptance. Regarding the question about the role of the generic medicines in the National Health System, 69.1\% agreed that they contribute to decrease the pharmaceutical expense in Spain, with decrease in the percentage while the education level decreased. On the contrary, $12.7 \%$ disagreed with this statement.

The majority $(66.1 \%)$ accepted the substitution process, although a $20 \%$ didn't and this percentage increases in the participants that had negative answers about the equivalence (71\%), effectiveness $(66 \%)$ and quality $(55 \%)$ of the generic medicines.

In tables 3 and 4 we can see the percentages of the participants that agreed or completely agreed with the positive statements about perception and attitude towards generic medicines, split by demographic characteristics of the participants.

\section{Aspects to consider when choosing a medicine}

We asked the participants about the aspects they considered important when choosing a medicine. Big majority pointed out the availability at pharmacies, followed by the prices, familiarity and availability on capsules, tablets and suspension as dosage form of the medicines (Graph 4. Aspects to consider when choosing a generic medicine).

\subsection{Discussion}

\section{DISCUSSION AND CONCLUSION}

Our goal was to research in the whole medicine chain with surveys to all the people that have a clear influence or major role. This is health professionals (doctors, nurses and pharmacists) and patients. This paper is focused in the patients perception and knowledge. In other countries similar surveys were done to patients and after the results it was concluded that the necessity of implementing training and/or incentives would improve the perception and knowledge, therefore the adherence to generic medicines, with the reduction of the pharmaceutical expense in the country and better service level to the patients. ${ }^{11-21}$

The results from this research show that in the majority of the participants, they know what a generic medicine is and in general they have a good perception about it. The results are consistent with the data from similar researches. ${ }^{1,3,22}$ Knowledge about differences between generics and branded was low (63.6\%) and even lower was the knowledge about the substitution process, only $41.3 \%$ stated they knew it. This is aligned with the results in similar research. ${ }^{7}$ Also the lack of knowledge on generics was linked to the negative answers about perception of the patients about its equivalence, effectiveness, quality and security. This negative perception because of lack of information is also reflected in the results of this research when we can see that one third of the participants had negative opinion about generics and they recognized that they didn't have enough information to understand the medicines they take.

A lower level of education was related with a lower knowledge of generic medicines and a worst perception of them, fact that was also reflected in other research conducted in Australia, Morocco, United States and Spain. ${ }^{1,2,6,23}$ Generally, the participants with better perception in generic medicines were younger than 30 years old, but nevertheless also a bigger proportion of this group admitted not to know the substitution process from branded to generics. Participants between 51 and 65 years old declared in bigger percentage to know the substitution process $(50 \%)$, probably driven to the fact that they are the group with higher medicine consumption, but at the same time, they declared not to have enough information to ensure they understand all the medicines they take $(25 \%)$ and not to accept the substitution process with almost $40 \%$ of their answers. We can see that the older the participants were, lower the substitution acceptance was. ${ }^{9,24}$ Also this age group was the one that more negatively answered about generics: more than one third declared that generics and branded are not equivalent, they have different quality and they are less effective than the branded ones.

On one hand $66 \%$ of the participants accept the substitution process, with the variables linked to the nonacceptance older age, low education level, low knowledge of generic medicines and bad perception about them. A previous research conducted in Spain demonstrated the same results, indicating also other factors linked to this push back not to take before generics or if the generic was prescribed by a specialist at hospital instead of the primary attention professional. ${ }^{15}$ The results indicate that in general the substitution process is well accepted and appreciated, fact that has been also seen in other countries like United States, Finland, France, Jordan, Germany, Australia or Japan. 1,3,7,8,10,11,25

On the other hand, from this analysis we see that the patients do not link usually the perception of different quality between generics and branded medicines with higher secondary effects in generics, as only 
$36 \%$ of the participants answered that they have different quality also stated that they had more secondary effects. The security of generic medicines has also been the best rated aspect of generics in other researches. ${ }^{3,5}$

\subsection{Conclusion}

In order to detect needs of information about generic medicines not covered in the patients, it is interesting to highlight the data that reflect a negative perception about them. From the whole group of participants, $23 \%$ considered that generics are less effective than branded, percentage quite similar to the ones obtained in other researches and in a similar proportion, they answered that they were not equivalent to branded medicines and were not the same quality. Participants answering negatively on equivalence, effectiveness and quality of generics showed a considerably lower acceptance to the substitution policy and a lower knowledge on generic medicines. ${ }^{1,5}$

The aspects that have been better rated by patients when choosing a medicine were the availability when buying it and the price. Price is also the factor that has more influence when choosing a medicine in other developed countries as United States, and in non-developed countries. ${ }^{11,26}$

We can conclude that this research highlight the need of a bigger effort in the country on generics information, especially in the group of older than 50 years old and in the lower education group. A better knowledge would facilitate a more responsible usage of them. ${ }^{12,14,18}$ Education campaigns by the government, health authorities or health professional groups would be the best stakeholders.

\subsection{Practice implications}

It's already demonstrated how the educational activities direct and individual about security and efficacy of generic medicines increases its acceptance and appreciation. ${ }^{24,27,28}$ Health professionals (doctors, pharmacists and nurses) are the ones in the best position to develop this educational work. ${ }^{20,22,29} \mathrm{~A}$ good communication doctor-patient in the therapeutic decisions phase with information about generic medicines and making sure the understanding of the medicines the patient is taking. . $^{15,19,21,30}$

Biggest and wider researches can help to design those educational campaigns.

\section{LIMITATIONS}

Questions on this survey were just about general aspects about perception of generic medicines and acceptance of the substitution process, without going into the detail of the patient to choose a generic medicine instead of a branded one. Patients in the study were randomly chosen at the pharmacy in Saragossa city. It is a study on a particular geographical region and a small sample. After the validation of this survey, a bigger scale study should be done in the country. The survey questions were just a bout general aspects about the perception of generic medicines and the acceptance of the substitution process, without checking the patient willness to choose between a generic or a branded medicine.

\section{Figures, Tables and Graphs}

Figure 1: Expert panel review questionnaire example

Table 1: Demographic data

Table 2: Positive answers about generic medicines knowledge (\%)

Table 3: Positive answers about perception and attitude towards generic medicines. Equivalence and effectiveness (\%)

Table 4: Positive answers about perception and attitude towards generic medicines. Quality, expense and acceptance (\%)

Graph 1: General generic medicines knowledge

Graph 2: Knowledge in generic medicines (\% of positive answers)

Graph 3: Positive perception and attitude towards generic medicines (\%)

Graph 4: Aspects to consider when choosing a generic medicine

\section{REFERENCES}

[1] Strategic Research Center, EAE Business School. [Pharmacy spent in Spain 2013. International evolution and situation from a national point of view]

[2] IMS Health. [Generic medicines market evolution]. 2013.

[3] AESEG, Asociación Española de Medicamentos Genéricos, IMS Health. [Workshop journalists Generic medicines market] 2010.

[4] IMS Institute. The Global Use of Medicines - Outlook through 2015. 2011. 
[5] ARMANDO, P.D. 2007. [ Development and validation of satisfaction surveys of patients with the service of essential pharmaceutical care in community pharmacies] ISBN: 978-84-338-4422-4. Tesis Dr. Farm, Universidad de Granada. Fac. Farmacia.

[6] Escribano Ruiz G, Fuentes Merino M, Alcaraz Criado J. [Marketing politics], Ed. Paraninfo, 2011.

[7] Pérez Andrés C. [Should the consensus techniques be included between the qualitative research techniques?] Revista Española de Salud Publica 2000; 74(4):319-22.

[8] Hasson F, Keeny S, McKenna H. Research guidelines for the Delphi survey technique. Journal of Advanced Nursing 2000; 32:1008-15.

[9] Argibay JC, Psychometric techniques. Validity and confidence questions. Subjectivity and cognitive processes]; 2006

[10] Sanchez R, Echeverry J. [Health measurement scales validation] Revista de Salud Pública 2004; 6(3): $302-18$.

[11] Shrank WH, Cox ER, Fischer MA, Mehta J, Choudhry NK. Patients' perceptions of generic medications. Health Affairs (Millwood). 2009; 28(2):546-56.

[12] Babar Z-U-D, Stewart J, Reddy S, Alzaher W, Vareed P, Yacoub N, et al. An evaluation of consumers' knowledge, perceptions and attitudes regarding generic medicines in Auckland. Pharmacy World \& Science. 2010; 32(4):440-8.

[13] Heikkilä R, Mäntyselkä P, Ahonen R. Do people regard cheaper medicines effective? Population survey on public opinion of generic substitution in Finland. Pharmacoepidemiology and Drug Safety. 2011; 20(2):185-91.

[14] Zaoui S, Hakkou F, Filali H, Khabal Y, Tazi I, Mahmal L. [Generic drug in Morocco: the point of view of the consumer]. Pan African Medical Journal. 2013; 15:18.

[15] Keenum AJ, Devoe JE, Chisolm DJ, Wallace LS. Generic medications for you, but brand-name medications for me. Research in Social Administrative Pharmacy. 2012; 8(6):574-8.

[16] Omojasola A, Hernandez M, Sansgiry S, Jones L. Perception of Generic Prescription Drugs and Utilization of Generic Drug Discount Programs. Ethnicity \& Disease. 2012; 22(4):479-85.

[17] Kobayashi E, Karigome H, Sakurada T, Satoh N, Ueda S. Patients' attitudes towards generic drug substitution in Japan. Health Policy. 2011; 99(1):60-5.

[18] Chong CP, March G, Clark A, Gilbert A, Hassali MA, Bahari MB. A nationwide study on generic medicines substitution practices of Australian community pharmacists and patient acceptance. Health Policy. 2011; 99(2):139-48.

[19] Iosifescu A, Halm EA, McGinn T, Siu AL, Federman AD. Beliefs about generic drugs among elderly adults in hospital-based primary care practices. Patient Education and Counseling. 2008; 73(2):377-83.

[20] Himmel W, Simmenroth-Nayda A, Niebling W, Ledig T, Jansen RD, Kochen MM, et al. What do primary care patients think about generic drugs? International Journal of Clinical Pharmacology Therapeutics. 2005; 43(10):472-9.

[21] El-Dahiyat F, Kayyali R. Evaluating patients' perceptions regarding generic medicines in Jordan. Journal of Pharmaceutical Policy and Practice. 2013; 6:3.

[22] Hassali MAA, Shafie AA, Jamshed S, Ibrahim MIM, Awaisu A. Consumers' views on generic medicines: a review of the literature. International Journal of Pharmacy Practice. 2009; 17(2):79-88.

[23] Sagardui-Villamor JK, Lacalle Rodríguez-Labajo M, Casado-Buendía S. [Substitution of generic for brand medicines in primary care. Factors associated to refuse the change]. Atención Primaria. 2005; 36(9):489-93.

[24] Blasco Oliete M, Torres Bouza C, Medina Bustillo B, Sanz Cuesta T, Neira León M. [Views of primary care users concerning generic medicines and the cost of medication]. Atención Primaria. 2003; 31(3):170-7.

[25] [Generic medicine perception by population] http://www.repere-medical.com/article-107.html. Consulted May 2104.

[26] Kohli E, Buller A. Factors influencing consumer purchasing patterns of generic versus brand name overthe-counter drugs. Southern Medical Journal. 2013; 106(2):155-60.

[27] Vallès JA, Barreiro M, Cereza G, Ferro JJ, Martínez MJ, Escribà JM, et al. A prospective multicenter study of the effect of patient education on acceptability of generic prescribing in general practice. Health Policy. 2003; 65(3):269-75.

[28] Sicras-Mainar A, Navarro-Artieda R. Physicians' and patients' opinions on the use of generic drugs. Journal of Pharmacology and Pharmacotherapeutics. 2012; 3(3):268-70.

[29] Ping CC, Bahari MB, Hassali MA. A pilot study on generic medicine substitution practices among community pharmacists in the State of Penang, Malaysia. Pharmacoepidemiology and Drug Safety. 2008; 17(1):82-9. 
[30] Frosch DL, Kaplan RM. Shared decision making in clinical medicine: past research and future directions. American Journal of Preventive Medicine. 1999; 17(4):285-94.

Table 1: Demographic data

\begin{tabular}{|l|l|l|}
\hline & Frequency & Percentage \\
\hline Gender & 62 & 37.6 \\
\hline Female & & \\
\hline Age & 103 & 62.4 \\
\hline $18-30$ years old & & \\
\hline $31-50$ years old & 23 & 13.9 \\
\hline 51-65 years old & 87 & 52.7 \\
\hline More than 65 years old & 36 & 21.8 \\
\hline Education & 19 & 11.5 \\
\hline None & & \\
\hline Basic studies & 2 & 1.2 \\
\hline Professional education, medium studies & 26 & 15.8 \\
\hline University degree & 47 & 28.5 \\
\hline Employment & 90 & 54.5 \\
\hline Unemployed & & \\
\hline Retired & 12 & 7.3 \\
\hline Employed & 23 & 13.9 \\
\hline Self-employed & 101 & 61.2 \\
\hline Student & 26 & 15.8 \\
\hline
\end{tabular}

Table 2: Positive answers about generic medicines knowledge (\%)

\begin{tabular}{|c|c|c|c|}
\hline & $\begin{array}{l}\text { I know the } \\
\text { differences } \\
\text { between a generic } \\
\text { and a branded } \\
\text { medicine }\end{array}$ & $\begin{array}{lr}\text { I know } & \text { the } \\
\text { substitution process } \\
\text { from branded to } \\
\text { generic medicine }\end{array}$ & $\begin{array}{lr}\text { I have enough } \\
\text { information } \\
\text { understand } & \text { to } \\
\text { medicines I take } & \end{array}$ \\
\hline \multicolumn{4}{|l|}{ Gender } \\
\hline Male & 24.2 & 17 & 26.1 \\
\hline Female & 39.4 & 24.3 & 38.7 \\
\hline Total & 63.6 & 41.3 & 64.8 \\
\hline \multicolumn{4}{|l|}{ Age } \\
\hline 18-30 years old & 8.5 & 3 & 8.5 \\
\hline $31-50$ years old & 35.7 & 23.1 & 33.9 \\
\hline $51-65$ years old & 12.7 & 10.9 & 13.9 \\
\hline More than 65 years old & 6.7 & 4.3 & 8.5 \\
\hline Total & 63.6 & 41.3 & 64.8 \\
\hline \multicolumn{4}{|l|}{ Education } \\
\hline None & 0.6 & 0.6 & 0.6 \\
\hline Basic studies & 6.6 & 6.1 & 7.3 \\
\hline Medium/Prof. education & 17 & 10.4 & 18.2 \\
\hline University degree & 39.4 & 24.2 & 38.7 \\
\hline Total & 63.6 & 41.3 & 64.8 \\
\hline \multicolumn{4}{|l|}{ Employment } \\
\hline Unemployed & 3.6 & 2.4 & 4.2 \\
\hline Retired & 7.9 & 5.5 & 10.3 \\
\hline Employed & 44.8 & 27.3 & 40 \\
\hline
\end{tabular}


Evaluation of patient's knowledge and perceptions regarding generic medicine

\begin{tabular}{|l|l|l|l|}
\hline Self-employed & 7.3 & 6.1 & 9.7 \\
\hline Student & 0 & 0 & 0.6 \\
\hline Total & 63.6 & 41.3 & 64.8 \\
\hline
\end{tabular}

Table 3: Positive answers about perception and attitude towards generic medicines. Equivalence and effectiveness $(\%)$

\begin{tabular}{|l|l|l|l|}
\hline & $\begin{array}{l}\text { Generics are } \\
\text { equivalent to } \\
\text { branded medicines } \\
\text { to }\end{array}$ & $\begin{array}{l}\text { Generics have } \\
\text { different } \\
\text { quality } \\
\text { branded } \\
\text { medicines }\end{array}$ & $\begin{array}{l}\text { Generics are less } \\
\text { effective to branded } \\
\text { medicines }\end{array}$ \\
\hline Gender & & & \\
\hline Male & 23 & 8.5 & 6.7 \\
\hline Female & 38.8 & 18.2 & 16.4 \\
\hline Total & 61.8 & 26.7 & 23.1 \\
\hline Age & & & \\
\hline 18-30 years old & 10.9 & 1.8 & 1.2 \\
\hline 31-50 years old & 32.7 & 14 & 10.9 \\
\hline 51-65 years old & 11.5 & 7.9 & 7.3 \\
\hline Older than 65 years old & 6.7 & 3 & 3.7 \\
\hline Total & 61.8 & 26.7 & 23.1 \\
\hline Education & & & \\
\hline None & 0 & 0.6 & 0.6 \\
\hline Basic studies & 6.7 & 4.9 & 5.5 \\
\hline Medium/Prof. education & 14.5 & 12.7 & 9.7 \\
\hline University degree & 40.6 & 8.5 & 7.3 \\
\hline Total & 61.8 & 26.7 & 23.1 \\
\hline Employment & & & \\
\hline Unemployed & 2.4 & 4.2 & 2.4 \\
\hline Retired & 8.5 & 3.7 & 4.9 \\
\hline Employed & 43 & 12.7 & 9.7 \\
\hline Self-employed & 7.3 & 5.5 & 6.1 \\
\hline Student & 0.6 & 0.6 & 0 \\
\hline Total & 61.8 & 26.7 & 23.1 \\
\hline & & \\
\hline
\end{tabular}

Table 4: Positive answers about perception and attitude towards generic medicines. Quality, expense and acceptance $(\%)$

\begin{tabular}{|l|l|l|l|}
\hline & $\begin{array}{l}\text { Generics have } \\
\text { more secondary } \\
\text { effects than } \\
\text { branded } \\
\text { medicines }\end{array}$ & $\begin{array}{l}\text { Usage } \\
\text { generics } \\
\text { contributes to } \\
\text { reduce the } \\
\text { pharmaceutical } \\
\text { expense }\end{array}$ & $\begin{array}{l}\text { accept the } \\
\text { substitution of } \\
\text { branded to generic } \\
\text { medicines }\end{array}$ \\
\hline Gender & & & \\
\hline Male & 4.2 & 27.3 & 23.6 \\
\hline Female & 7.3 & 41.8 & 42.5 \\
\hline Total & 11.5 & 69.1 & 66.1 \\
\hline Age & & & \\
\hline 18-30 years old & 0.6 & 8.4 & 10.9 \\
\hline 31-50 years old & 5.5 & 36.4 & 37 \\
\hline 51-65 years old & 4.2 & 15.8 & 10.9 \\
\hline Older than 65 years old & 1.2 & 8.5 & 7.3 \\
\hline Total & 11.5 & 69.1 & 66.1 \\
\hline Education & & & \\
\hline
\end{tabular}




\begin{tabular}{|l|l|l|l|}
\hline None & 0 & 0 & 0.6 \\
\hline Basic studies & 4.3 & 7.9 & 6.1 \\
\hline Medium/Prof. education & 4.2 & 18.8 & 14.5 \\
\hline University degree & 3 & 42.4 & 44.9 \\
\hline Total & 11.5 & 69.1 & 66.1 \\
\hline Employment & & & \\
\hline Unemployed & 0.6 & 5.5 & 4.8 \\
\hline Retired & 2.4 & 11.5 & 7.9 \\
\hline Employed & 4.9 & 42.4 & 44.9 \\
\hline Self-employed & 3.6 & 9.7 & 7.9 \\
\hline Student & 0 & 0 & 0.6 \\
\hline Total & 11.5 & 69.1 & 66.1 \\
\hline
\end{tabular}

Figure 1: Expert panel review questionnaire example

\section{PART I: Knowledge EFG's}

\section{Question in the survey}

- Do you know what a generic medicine is?

$$
\begin{aligned}
& - \text { YES } \\
& -N O \\
& -N / A
\end{aligned}
$$

\section{Review}

\section{A. CONTENT}

Is the question necessary?

\begin{tabular}{|c|c|c|}
\hline Could it be explained in a clearer way? & $\Gamma_{1}$ & $\Gamma_{1}$ \\
\hline How? & & \\
\hline Can it have different interpretations? & $\Gamma_{1}$ & $\Gamma_{1}$ \\
\hline Does it have any prejudment? & $r_{1}$ & $\Gamma_{1}$ \\
\hline C. PLACEMENT & & \\
\hline Is it placed in the correct place? & $\Gamma_{1}$ & $\Gamma_{1}$ \\
\hline Can the previous question(s) influence? & $\Gamma_{1}$ & $\Gamma_{1}$ \\
\hline
\end{tabular}

Is it necessary to concrete more?

B. WRITING

Graph 1: General generic medicines knowledge

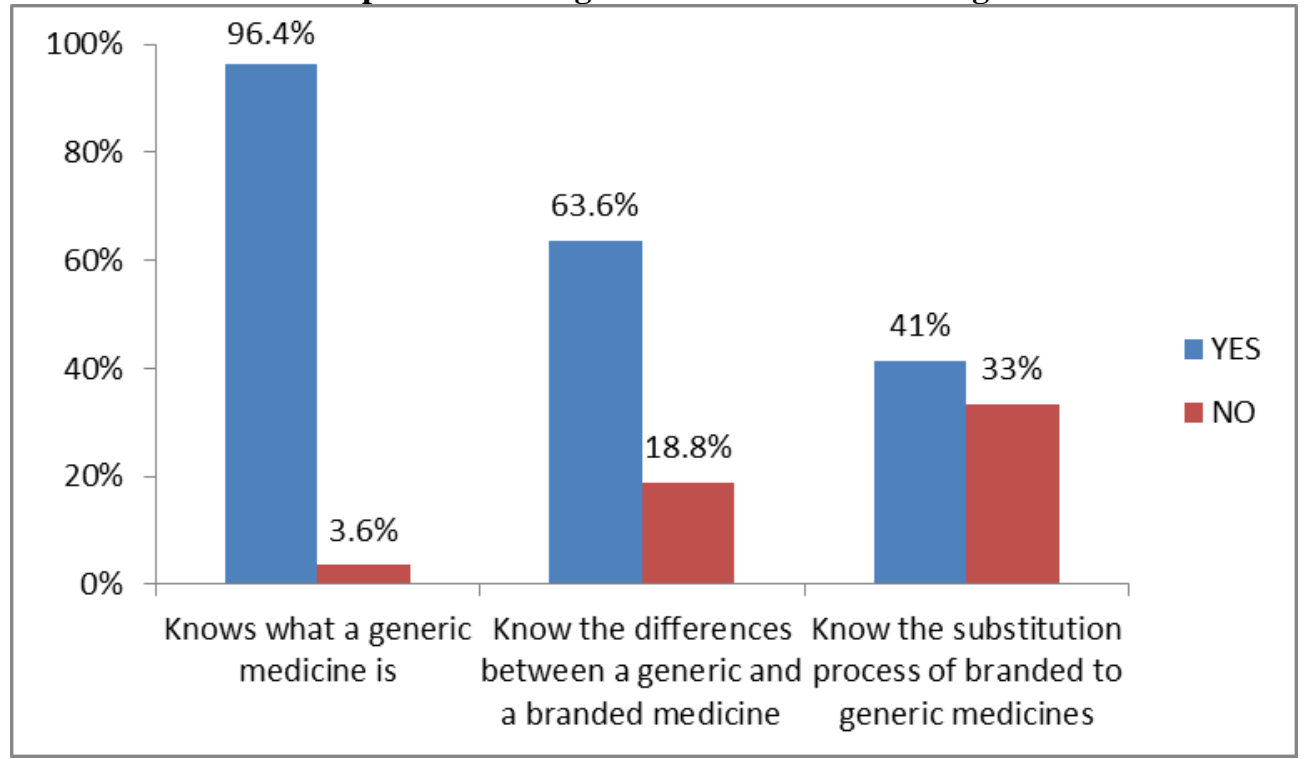


Graph 2: Knowledge in generic medicines (\% of positive answers)

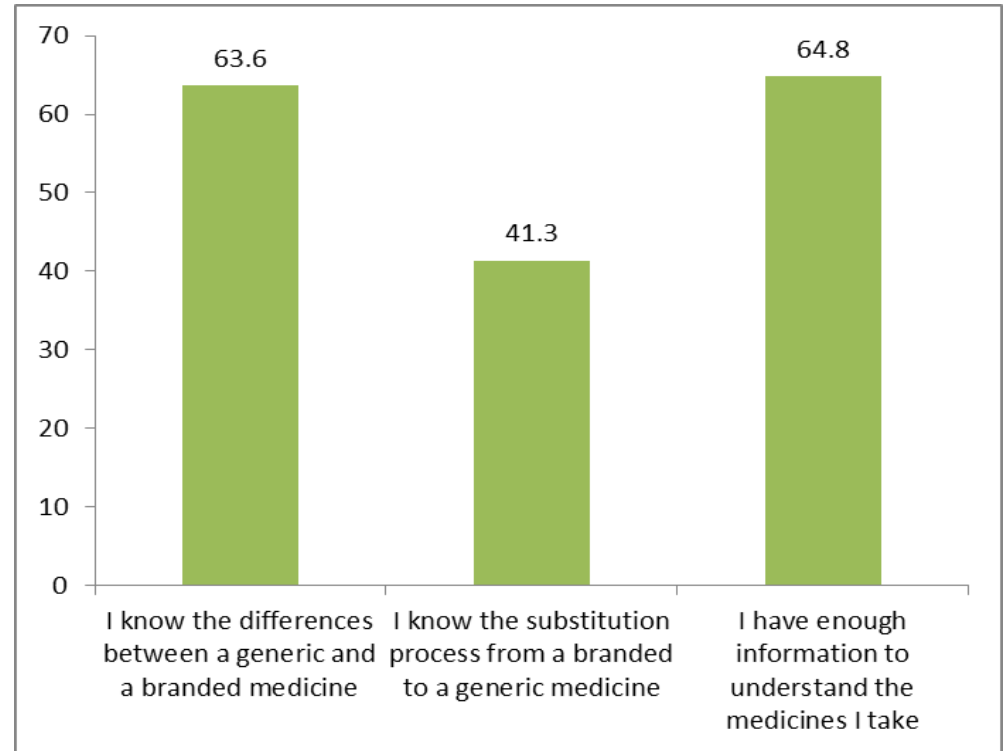

Graph 3: Positive perception and attitude towards generic medicines (\%)

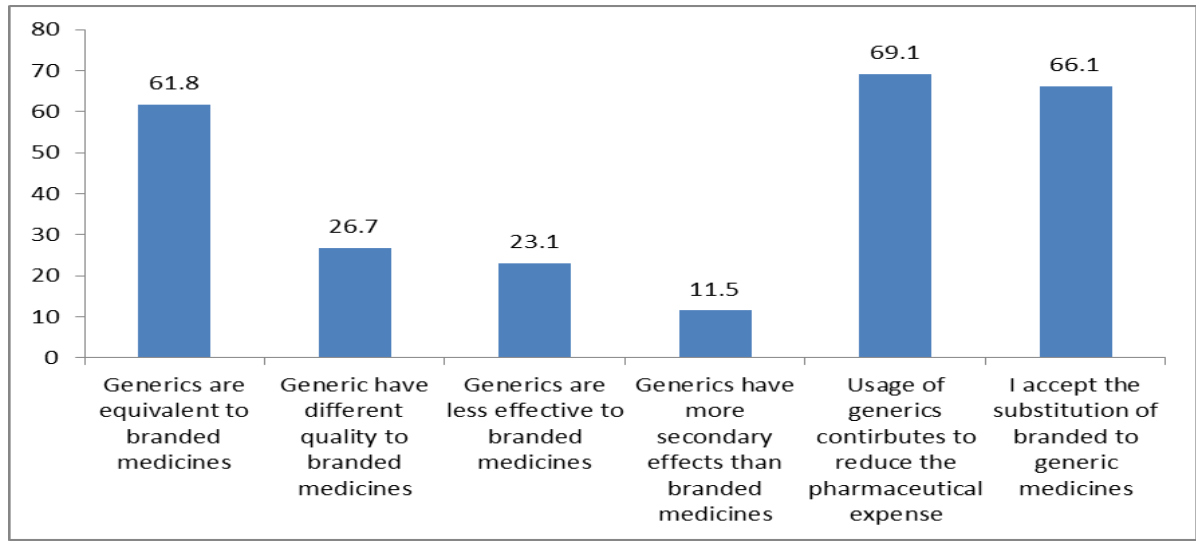

Graph 4: Aspects to consider when choosing a generic medicine

\section{What do you consider when choosing a medicine?}

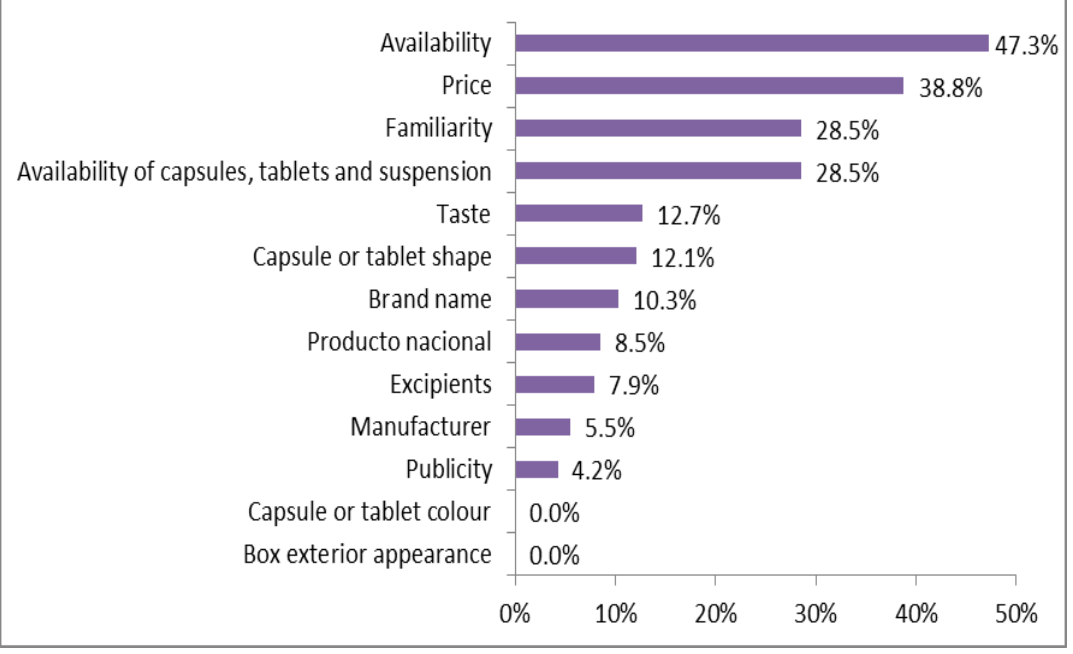

